\title{
Pedro Henríquez Ureña y su recuperación editorial de las obras sorjuaninas
}

Fecha de recepción: marzo 2021 Fecha de aceptación: junio 2021

\begin{abstract}
Resumen $^{1}$
Las Obras completas de sor Juana son consideradas un hito para la consolidación de su figura como parte fundante del canon latinoamericano. Desde que las obras de sor Juana dejan de reimprimirse en 1725 , diversos intelectuales a lo largo de dos siglos participaron parcialmente en su recuperación. Uno de ellos fue Pedro Henríquez Ureña, que desde 1914 pugna por la edición de las obras sorjuaninas. El presente artículo estudia las aportaciones del dominicano al campo de estudios acerca de la monja a la vez que enfatiza la publicación de Obras completas como parte de la Colección Biblioteca Americana, ideada por el dominicano a partir de la petición de Daniel Cosío Villegas, director de Fondo de Cultura Económica. De esta manera, se analiza la manera en que la revaloración del barroco americano por Henríquez Ureña, así como su labor editorial, afincaron el proyecto de las Obras completas.
\end{abstract}

PALABRAS CLAVE: Sor Juana, Pedro Henríquez Ureña, Colección Biblioteca Americana, barroco latinoamericano

\section{"Pedro Henríquez Ureña and the editorial recovery of sor Juana Inés de la Cruz's works"}

\begin{abstract}
Obras completas de sor Juana are considered an important event in the nun's consolidation as a fundamental figure of Latin American canon. Since 1725, sor Juana's works were not reprinted. Nonetheless, a diverse array of intellectuals participated in her partial recuperation on the following two centuries. One of them was Pedro Henríquez
\end{abstract}

1 El presente artículo se desprende de mi tesis doctoral "Sor Juana o la construcción de un ícono nacional (circa 1870-1970)". 
Ureña, that since 1914 advocated for sor Juana's editions. The present article studies Henríquez Ureña's contributions to the field, emphasizing the publication of Obras completes as part of an editorial project, the Colección Biblioteca Americana, created by the Dominican after being petition by Daniel Cosío Villegas, director of the Fondo de Cultura Económica. Furthermore, it analyzes the reevaluation of the Latin American baroque by Henríquez Ureña, as well as his editorial enterprise, an who it contributed to the publication of Obras completas.

KEYWORDS: Sor Juana, Pedro Henríquez Ureña, Colección Biblioteca Americana, Latin-American baroque

\section{"Pedro Henríquez Ureña e a recuperação editorial das obras de Sor Juana Inés de la Cruz"}

\section{Resumo}

As Obras Completas de Sor Juana são consideradas um marco para a consolidação de sua figura como parte fundadora do cânone latino-americano. Desde que as obras de Sor Juana deixaram de ser reimpressas em 1725, vários intelectuais ao longo de dois séculos participaram parcialmente de sua recuperação. Um deles foi Pedro Henríquez Ureña, que desde 1914 luta pela edição das obras de Sor Juana. Este artigo estuda as contribuições dos dominicanos ao campo dos estudos sobre a freira, ao mesmo tempo em que destaca a publicação de Obras completas como parte da Colección Biblioteca Americana, idealizada pelo dominicano a pedido de Daniel Cosío Villegas, diretor do Fundo de Cultura Econômica. Analisa-se assim a forma como a reavaliação de Henríquez Ureña do barroco americano, bem como a sua obra editorial, instituíram o projeto Obras Completas.

PALAVRAS-CHAVE: Sor Juana, Pedro Henríquez Ureña, Colección Biblioteca Americana, barroco latino-americano.

La restitución de Sor Juana y el proceso de su recuperación editorial a mitad del siglo XX son el resultado de varios actores en el campo cultural. Si bien está documentado el influjo de algunos de los Contemporáneos ${ }^{2}$ o de Octavio Paz en este proceso, no se ha exaltado lo suficiente la aportación de Pedro Henríquez Ureña a los estudios sorjuaninos. En gran medida, es posible argumentar que la consolidación de sor Juana como figura canónica resulta en la publicación de sus obras completas a cargo de Alfonso Méndez Plancarte. Los primeros tres tomos Lírica personal (1951), Villancicos y letras sacras (1952) y Autos y loas (1955)- son editados por Méndez Plancarte pero, tras su muerte en 1955, el último volumen, titulado Comedias, sainetes y prosa (1957), lo concluye Alberto G. Salceda. Sin embargo, es necesario encuadrar el proyecto

\footnotetext{
2 Este nombre le fue asignado a posteriori por la historiografía literaria al grupo de escritores que se reúne en torno a la revista homónima, publicada entre el 15 de junio de 1928 y el 1 de diciembre de 1931. Al no lanzar un manifiesto, la discusión acerca de quiénes forman parte de los Contemporáneos sigue sin resolverse. Sigo a Guillermo Sheridan, Los Contemporáneos ayer, quien establece que el grupo está compuesto por dos subgrupos diferenciados por la edad de sus miembros: el primero conformado por Jaime Torres Bodet -destacado diplomático y funcionario público-, Bernardo Ortiz de Montellano -director de la revista desde el nº 10 hasta el final de la publicación-, Enrique González Rojo -hijo del poeta Enrique González Martínez-y José Gorostiza -autor de Canciones para cantar en las barcas y Muerte sin fin; en el segundo subgrupo se encuentran Xavier Villaurrutia -conocido por Nocturnos, Nostalgia de la muerte y por su crítica de artes plásticas-, Salvador Novo -poeta y cronista incansable de la Ciudad de México-, Jorge Cuesta -ensayista y autor del poema "Canto a un dios mineral” publicado póstumamente-y, por último, Gilberto Owen, quien en Novela como nube y Perseo vencido da muestras de innovaciones vanguardistas. La nómina del grupo varía de crítico en crítico. Al no lanzar un manifiesto, la discusión acerca de quiénes forman parte de los Contemporáneos sigue sin resolverse.
} 
como parte de otro mayor: la Colección Biblioteca Americana del Fondo de Cultura Económica, proyecto ideado por Pedro Henríquez Ureña. Es imposible señalar al dominicano como el único involucrado en la restitución de la obra sorjuanina. Sin embargo, desde la primera década del siglo XX, promueve la edición de las obras sorjuaninas; exhorto que se concreta con la publicación de las Obras completas.

Para situar la importancia de esta publicación, así como del proceso en el que la monja se reincorpora al imaginario nacional, es necesario hacer un trazado de las ediciones de Sor Juana y la manera en que estas desaparecen del panorama editorial en el siglo XVIII hasta su regreso a mediados del siglo XX. Durante la vida de la monja, se imprimieron dos volúmenes compilatorios y uno póstumo: "el primero, la Inundación castálida, se publicó en 1689 a cargo de Juan Camacho Gayna; el Segundo volumen, que vio la luz en 1692, se imprimió por petición del dedicatario del mismo, Juan de Orúe y Arbieto; y el tercero, titulado Fama y obras pósthumas, del año 1700, salió gracias a los esfuerzos de Juan Ignacio de Castorena" (Pérez González, 2018: 238). Martha Lilia Tenorio, al comentar sobre las reediciones de los tres tomos, señala que, "el primero, con el título de Poemas (cambio que hizo seguramente sor Juana; quizá no le gustó eso de 'inundación en aguas de Castalia', la fuente de las musas), se reeditó, de 1690 a 1723, ocho veces. El segundo con el título de Segundo tomo o de Obras poéticas, de 1693 a 1725, se reimprimió tres veces" (2018: 18). La poeta deja de ser leída durante el siglo XVIII, pues "hacia 1750 ya no era fácil encontrar en una librería las obras de la monja ... No había ya demanda, pues los gustos estaban cambiando" (Alatorre, 2007a: 51). Cuestiones como su genio permiten que perviva su nombre, pero el desdén por el gongorismo y la función pragmática de construcción nacional que se le asigna a la literatura en el siglo XIX hacen que su poesía caiga en el olvido.

Pedro Henríquez Ureña es uno de los principales restituidores de Sor Juana desde la veta editorial. En "Sor Juana Inés de la Cruz", traza las ediciones sorjuaninas posteriores a las reimpresiones de 1725 . El dominicano afirma que al comenzar el siglo XVIII, la relación de Sor Juana con el gongorismo la relegó, pues "se le consideraba su discípula, quedaba olvidada y condenada por el culteranismo gongorino" (2004: 60). Sin embargo, señala a quienes han impulsado, a su parecer, la obra de la monja: los liberales Ignacio Ramírez "El Nigromante” y José María Vigil. A pesar de su lectura, sobredimensiona los aportes de "El Nigromante" al sorjuanismo, pues este no creía que la monja debiera ser incluida como parte de la tradición mexicana. ${ }^{3}$ La segunda persona a la que exalta Pedro Henríquez Ureña es a José María Vigil, director de la Biblioteca Nacional. A diferencia de Ramírez, los trabajos de Vigil pueden fácilmente considerarse un antecedente de la recepción favorable de la monja; el dominicano destaca la aportación de Vigil a la velada en honor a Sor Juana, la Antología de poetisas mexicanas. Siglos XVI, XVII, XVIII y XIX para la Exposición de Chicago y la "Reseña histórica de la poesía mexicana", introducción a la Antología de poetas mexicanos. ${ }^{4}$

Sin embargo, a pesar de las contadas excepciones, lo que predomina es el desconocimiento de la obra sorjuanina. La imposibilidad de acceder a sus publicaciones, que explica Henríquez Ureña, demuestra que "[1]a falta de acceso a las obras escritas se

\footnotetext{
3 La postura de Ramírez ante Sor Juana queda clara cuando, en 1874, impugna la velada que el Liceo Hidalgo, la asociación literaria más importante de la segunda mitad del siglo XIX, organiza en honor a la monja. En la velada, posteriormente publicada como Composiciones, leídas en la velada literaria que consagró el Liceo Hidalgo a la memoria de Sor Juana Inés de la Cruz la noche del 12 de noviembre de 1874, aniversario del natalicio de la ilustre poetisa, el conservador José de Jesús Cuevas menciona que la monja, junto con Nezahualcóyotl y el poeta conservador Manuel Carpio, encabeza el Parnaso mexicano y que, la poesía mexicana, al tener a la poeta novohispana como madre, podrá regresar a la corriente católica que ata la tradición (1874: 99-100). Ignacio Ramírez exclama: "Ha probado usted, en resumen, que pudieran agregarse al calendario tres santos, pero no que México pueda enorgullecerse de tener tres poetas. Ha confundido usted dos cuestiones diversas, la de la estética y la del misticismo" (cfr. en Alatorre, 2007b: 331). Para una reconstrucción de la velada en honor a Sor Juana, ver Belem Clark de Lara (2008).

4 Para un análisis del papel de Vigil en la restitución sorjuanina, ver Quijano (2005).
} 
empieza a convertir en sonada excusa de su desconocimiento" (Perelmuter, 2004: 99). El dominicano señala que durante el siglo XIX se hicieron tres ediciones, pero no de sus obras completas: la biografía de Juan de León Mera (Ecuador), los trabajos de Antonio Elías de Molins (España) y los de la casa Donnamette (Francia); califica la primera edición como buena, la segunda como escandalosa y la tercera como mediana. A esto le suma el trabajo de Juan María Gutiérrez, Sor Juana Inés de la Cruz. Escritora americana, siglo XVII, la Antología de poetas hispano-americanos de Menéndez Pelayo, y la inclusión de una comedia de Sor Juana en la Biblioteca de autores españoles (2004: 60-61). Martha Lilia Tenorio agrega un grupo de escritores a los que llama "agudos", pues a pesar de que la estética sorjuanina estaba en desuso, la defienden. Además de los mencionados por Henríquez Ureña, añade a don Santos Pina y Guasquet, por su "Discurso", y a Nemesio García Naranjo, por su "Biografía de Sor Juana Inés de la Cruz" (2008: 518-521). ${ }^{5}$ La persistencia de ediciones sorjuaninas y estudios críticos fuera de México -con algunas excepciones- hace más notoria la ausencia de ediciones nacionales durante el siglo XIX y las primeras décadas del XX. Esta situación da cuenta de la imbricación entre los proyectos nacionales y la recepción de la monja, y de qué manera este fenómeno discordante impide una lectura como la que se realiza fuera de los confines del Estado. El itinerario editorial de sus obras se encuentra en la encrucijada del momento entre razones artístico- políticas: el rechazo al gongorismo por cuestiones estéticas como resultado del Neoclasicismo, primero, y del Romanticismo, después; y políticas: la relación de la monja con los virreyes, que los letrados creen que muestra la sumisión novohispana ante el dominio español. ${ }^{6}$

Como antecedente difuso de la defensa de Pedro Henríquez Ureña en pro de la publicación de las obras sorjuaninas se encuentra su propia participación en la Antología del Centenario. Estudio documentado de la literatura mexicana durante el primer siglo de la independencia, que solo llega a concretar sus dos primeros volúmenes bajo la dirección de Justo Sierra, Ministro de Instrucción y Bellas Artes. ${ }^{7}$ La Antología es elaborada por Luis G. Urbina, Pedro Henríquez Ureña y Nicolás Rangel y se publica en 1910 por la Imprenta de Manuel León Sánchez. ${ }^{8}$ En el "Estudio Introductorio", escrito por Luis G. Urbina, se menciona brevemente a Sor Juana, y se señala cómo tras haber renunciado a la escritura, deja un vacío (1910: XII). La Antología la presenta como "monja apasionada y genial", pues es "la profunda Sor Juana Inés de la Cruz, cuyos divinos discreteos, en cuyos aéreos y luminosos alambicamientos, como en urdimbres tejidas con rayos de sol, se enredaron para siempre los sueños y los desengaños de un amor misterioso y sin esperanza" (ibídem). La oscuridad que había imperado al describir la poesía de Sor Juana es ahora "luz". Pedro Henríquez Ureña, como uno de los compiladores, presenta en el recuento histórico a Sor Juana como elemento crucial para comprender el pasado y el presente de las letras mexicanas. Sin embargo, como atestigua en "En pro de una edición definitiva de Sor Juana", el rescate de las obras sorjuaninas sigue como tarea pendiente.

El desconocimiento generalizado de la obra de la monja es una preocupación constante en las reflexiones de Pedro Henriquez Ureña. ${ }^{9}$ En el artículo "En pro de una edición definitiva de Sor Juana" (1914) hace un llamado a publicarla. Menciona que

\footnotetext{
5 Para un recuento detallado de las publicaciones sorjuaninas a partir de la aparición de las Obras completas y cómo complican la noción de "obra”, ver Fumagalli (2018).

6 Aunque a partir de la historiografía literaria liberal, González-Stephan (2002) explica las coordenadas políticas de la reacción negativa ante el gongorismo.

7 Para un estudio de la Antología del Centenario y su impacto en la construcción de un canon nacional, ver Sánchez Prado (2010).

8 En 1910 aparece un texto fundamental en el proceso de construcción de Sor Juana como ícono nacional mexicano: Juana de Asbaje de Amado Nervo.

9 Para un esbozo de la historia de la recepción de Sor Juana ver Perelmuter (2004).
} 
si la edición de la obra de Gertrudis Gómez de Avellaneda tiene carácter de urgencia, “¡cuánto más lo es la de Sor Juana, cuyo texto legítimo es desconocido del vulgo! Sus versos corren, estragados, por todas las antologías, y sólo en la de Poetas hispanoamericanos de Menéndez y Pelayo se han reproducido con exactitud" (2011: 234). Comenta que "el decoro literario exige se restablezca el texto de Sor Juana" (ibídem). Ya sea que el gobierno asuma los gastos de la edición o que la labor sea realizada por un literato, en cualquier caso "deberá acudirse a las ediciones antiguas, pero no sólo a una, sino a varias, para cotejarlas y anotar sus variantes procurando además establecer una clasificación cronológica de las composiciones" (ibídem). Henríquez Ureña pide un trabajo filológico cuidadoso, capaz de revertir el desconocimiento de la obra: "No es excesivo homenaje para la poetisa la total y cuidadosa impresión de sus obras" (ibídem: 234-235). El proyecto, anunciado muy tempranamente en la carrera literaria de Pedro Henríquez Ureña, no se cristaliza sino hasta 1951.

Antes de la publicación de las Obras completas, quienes comienzan las ediciones sorjuaninas, aunque a cuentagotas, son los autores del grupo Contemporáneos. Por ejemplo, Poesía de Sor Juana Inés de la Cruz, estudio de Manuel Toussaint, de la editorial CVLTVRA, con José Gorostiza como director; los diversos estudios de la obra sorjuanina publicados en la revista Contemporáneos de 1928 a 1931, sobre todo de la pluma de Ermilo Abreu y de Dorothy Schons; la publicación de Sonetos y endechas de SorJuana, en 1941, con edición y notas de Xavier Villaurrutia; y, por último, el catálogo para la "Exposition du Livre Mexicain" realizada en la Université de Paris, en 1955, cuando Torres Bodet es embajador. A través de dichos materiales se reapropian de la figura sorjuanina y la difusión de su obra se presenta en formatos más accesibles que, a su vez, crean nuevos espacios para la transmisión. ${ }^{10}$

Ermilo Abreu Gómez es una figura fundamental en esta etapa de recuperación editorial de las obras de Sor Juana. Para Eduardo José Tello Solís, las investigaciones del yucateco "son un parteaguas en los estudios sobre esta poetisa mexicana" (2008: 12). En Semblanza de Sor Juana, Abreu Gómez revisa la crítica, época, vida y obra de la monja. El autor cree que "es preciso llegar al siglo XX para advertir la iniciación de una crítica veraz, elaborada sobre documentos y apoyada en ordenaciones justas, filosóficas, equidistantes de la negación fanática como de la afirmación panegirista" (1938: 16). Destaca la labor de Pedro Henríquez Ureña, Dorothy Schons, Manuel Toussaint y Luis González Obregón, por sus diversas aportaciones a los estudios sorjuaninos. Sin embargo, son las críticas a su trabajo en Sor Juana Inés de la Cruz. Bibliografía y biblioteca las que terminaron por descartarlo como el editor de sor Juana.

El padre Méndez Plancarte responde a los trabajos de Abreu Gómez, en particular a Bibliografía y biblioteca (1934), en diez artículos publicados primero en Ábside y luego en El Universal a partir de $1944 .{ }^{11}$ Posteriormente, Octaviano Valdés los compila con el título Crítica de críticas sorjuaninas. Para cuando Méndez Plancarte comienza a contestar a Abreu Gómez, había publicado en 1942 y 1943 los primeros dos tomos de Poesía novohispana, y el tercero estaba en camino (Herrera Zapién, 2005: 153). El padre revisa detalladamente las publicaciones de Abreu Gómez y ante la fama del yucateco dice: "[m]ás trágica, por ello, la disparidad del ruido y las nueces, cuando un sereno examen directo en vano le busca esa plenitud y solidez documental y esa

10 Jiménez del Campo (2005) sitúa los estudios de las décadas de los veinte y los treinta como el inicio de la canonización de Sor Juana en tres vertientes: editorial, crítica y artística (213). Menciona, además, las ediciones de Villaurrutia -Sonetos (1931) y Endechas (1940)-, las diversas apariciones de estudios sobre Sor Juana y de poemas de la monja en Contemporáneos; $y$, finalmente, analiza la influencia de "Primero sueño" en los poemas "Nostalgia de la muerte" de Villaurrutia, "Muerte sin fin de Gorostiza", "Canto a un dios mineral" de Cuesta y "Simbad el varado" de Owen (214216). Por su parte, Stanton (1998) estudia el diálogo entre la creación literaria del grupo y el poema "Primero sueño", con especial atención a "Muerte sin fin” de José Gorostiza.

11 Para más información sobre las particularidades de las respuestas de Méndez Plancarte, ver Herrera Zapién (2005). 
probidad profesional de investigador que sólo asienta lo que sabe y que trabaja a conciencia" (1982: 50). Para él, refutarlo es un "llano caso de higiene pública" (ibídem: 51). Finalmente, desmonta los trabajos de Abreu como sorjuanista y expone las imprecisiones que encuentra en ellos.

Méndez Plancarte señala errores en la catalogación que hace Abreu Gómez de la biblioteca de sor Juana: referirse a André Tiraqueu, quien escribe el tratado "De Legibus Connubialibus", por el nombre de CONNUB ("le infundió aquí vida personal y autónoma nuestro brillante metamorforseador de libros en gente") (ibídem: 69); Abreu funde a Plinio, el menor, con Plinio, el viejo, "pasando ya a la opuesta 'merlinesca' - la de la 'compenetración de personalidades, por unificación de gente" (ibídem: 70); el yucateco confunde personajes con autores, como Rómulo, fundador de Roma, a quien menciona como Augustus Romulus del siglo XIII y escritor de fábulas; Abreu Gómez comete errores estilísticos, como escribir que el dístico latino se compone de dos hexámetros, no de un hexámetro y un pentámetro (ibídem: 75); y, por último, Méndez Plancarte señala la ausencia de la Biblia como lectura de Sor Juana, según la ausencia de ella en Bibliografía y biblioteca. Estas, entre muchas otras inexactitudes, hacen que Méndez Plancarte termine por clasificar la obra de Abreu Gómez y su fama como "tragicómica y nacionalmente bochornosa disparidad" (ibídem: 87). Su crítica es contundente.

Para entender cómo es que Méndez Plancarte es el encargado de las Obras completas y el papel que desempeña Pedro Henríquez Ureña es necesario situar los cuatro tomos no como estudios aislados, sino como parte de un proyecto más ambicioso: la Colección Biblioteca Americana. Esta comienza con el deseo de Daniel Cosío Villegas, director del Fondo de Cultura Económica, de crear una nueva colección. Por ello, le escribe a su amigo dominicano a Buenos Aires, el 18 de abril de 1945, para invitarlo a conformar el programa de una nueva colección y solicitarle un plan para "sacar a flote lo mejor que hayan escrito los hispanoamericanos de todos los países y de todos los tiempos" (Correspondencia: 9). Este le contesta que había comenzado en la editorial Losada una colección similar, pero que marchaba lento, por lo que acepta la proposición de "redactar el plan" (ibídem: 4). Ambos deciden que, aunque el dominicano haga el programa, la encargada de la Colección será Camila Henríquez Ureña, su hermana.

La creación del plan permite comprender cómo es que el dominicano entiende la colección, pues al mencionar su nombre, alterna entre "Biblioteca Americana (ibídem: 17) y "La tradición de América" (ibídem: 38). Liliana Weinberg entiende la Colección como una estrategia cultural y una política de lectura con un plan a largo plazo que tiene como antecedente el proyecto de Andrés Bello y Juan García del Río, la "Biblioteca Americana, o Miscelánea de la literatura, artes y ciencias", de 1823. Weinberg señala que la Colección tiene diversas funciones: construye una tradición, da cuenta de la existencia de obra escrita en América, constituye un conjunto que al quedar abierto designa el comienzo de la colección, se presenta como un examen del pasado y el futuro, busca crear un nuevo sector de lectores y, por último, muestra un fin ético al buscar promover los valores americanos. ${ }^{12}$ Es por eso que estudiar la manera en que las Obras completas de sor Juana se insertan en la Colección da cuenta de una revaloración de la escritura de la monja como parte de una lógica de la tradición particularmente americana que incluye al barroco en ella.

12 Weinberg reconstruye la fundación del proyecto por medio de dos documentos: la correspondencia clasificada con los números 155, 156 y 157 del Archivo Histórico del Fondo de Cultura Económica (AHFCE), que incluye correspondencia de Daniel Cossío Villegas con Pedro Henríquez Ureña y con Camila Henríquez Ureña, así como el catálogo de apertura de la publicación de 1946. Para la presente investigación, se consultaron los mismos materiales del AHFCE, por lo que cuando se hace referencia a ellos en el texto, se mencionará como Correspondencia y el folio, ya que pertenecen en su totalidad al legajo 155 . 
Dentro del proyecto, la literatura novohispana ocupa un sitio destacado. Cuando Pedro Henríquez Ureña nombra a los autores novohispanos, comenta que "hasta ahora nunca se han reimpreso completas las obras de sor Juana" (Correspondencia: 46). El 22 de marzo de 1946, propone su plan editorial para revertir la situación y comienzan a discutir con Cosío Villegas quién debe ser el editor. El primer nombre que menciona es el de Manuel Touissant, que había publicado, en la Editorial CVLTVRA, Poesía escogida de sor Juana Inés de la Cruz (1916) y Poemas inéditos, desconocidos y muy raros de sor Juana Inés de la Cruz (1926), en la editorial Imprenta de Manuel León Sánchez. Con esto en mente, Henríquez Ureña le escribe a Cosío Villegas:

\begin{abstract}
Sor Juana: las poesías -líricas- completas se han publicado hace poco en México; yo sugiero una edición de la obra en verso completa, es decir, incluyendo las comedias, los autos y los villancicos. Esto ocupará más de un volumen. Sería cosa de decidir primero cuál de los volúmenes debe salir antes: podría ser, por ejemplo, uno de autos y villancicos; quizá el segundo podría llevar las comedias; el tercero, o el tercero y el cuarto, las poesías. Si los volúmenes son grandes uno podría llevar todo lo de forma dramática y otro todo lo de forma lírica. Creo conveniente comenzar con lo dramático, porque lo lírico se ha hecho mucho; si fuesen cuatro tomos, comenzar con los villancicos y autos, que es lo menos manoseado. A pesar de que Toussaint esté dedicado al arte, creo que no le sería difícil hacer el prólogo, porque domina el tema, y además escribe muy bien. ¡Qué descanso! (Correspondencia: 69)
\end{abstract}

A pesar del entusiasmo, Cosío Villegas no comparte la elección del editor, por lo que le responde a Pedro Henríquez Ureña, el 3 de mayo, que ha solucionado la cuestión y encomendado el trabajo:

\begin{abstract}
El problema de sor Juana era realmente difícil: tu sugestión de Manuel Toussaint no era válida, cuando más, sino para los prólogos; pero en general, la persona que trabaja en los textos ambiciona hacer el prólogo y las notas, sobre todo cuando se trata de un caso semejante a éste. Descartado Toussaint, quedaban Ermilo Abreu Gómez, que ha pasado por un especialista durante años, y quizás Francisco Monteverde. No sé si te enteraste que Alfonso Méndez Plancarte publicó primero, en su Revista Ábside, después, en El Universal, una serie de artículos destrozando la obra de Ermilo. Esto me condujo a pensar en Méndez Plancarte como un candidato para establecer el texto definitivo y hacer las notas y prólogos. Le escribí dándole a conocer las sugestiones que tú me habías hecho, y te adjunto una copia de su carta para que juzgues y me des tu impresión. En todo caso, el hombre ha aceptado la faena y principia a trabajar con todo el compromiso de entregar para noviembre el primer tomo. Alfonso Reyes ha aceptado escribir el prólogo (Correspondencia: 80)
\end{abstract}

Al parecer, la refutación de Méndez Plancarte le parece apropiada y justa a Cosío Villegas. Aunque bajo criterios distintos, Méndez Plancarte acepta la sugerencia de los cuatro tomos que hace Henríquez Ureña, pero a diferencia de lo que propone el dominicano, empieza por la lírica sorjuanina, además de que deja los autos y las comedias para el final. Cabe mencionar que Alfonso Reyes no escribe el prólogo de las Obras completas.

La inclusión de Sor Juana en una colección americanista y la voluntad de editarla muestran un cambio en la interpretación del barroco. Diversos escritores buscan en el barroco americano la legitimidad histórica de la tradición literaria del continente. Al integrarla en una colección que tiene como objetivo publicar las obras representativas de la tradición literaria americana, Sor Juana deja de ser la novohispana apátrida, para convertirse en referente latinoamericano. Las Obras completas son el resultado del enfrentamiento Méndez Plancarte vs. Abreu Gómez y de la voluntad de Henríquez Ureña. La relectura del dominicano considera a Sor 
Juana parte fundante del pensamiento latinoamericano. Su publicación muestra la recuperación del barroco de Indias como fundante de la historia literaria americana, proceso que se puede entender a la luz de la apropiación del barroco que surge a mediados del siglo XX y que, a la par de los debates nacionales, hace de Sor Juana un referente fundamental. Henríquez Ureña, en Seis ensayos en busca de nuestra expresión (1928), reflexiona sobre las particularidades de la tradición en la literatura americana. Escribe que, tras la independencia política, se busca su correlato en el plano literario, por lo que la generación de la Independencia, en la que incluye a Bello, Gutiérrez, Olmedo, Heredia, Lizardi y Bartolomé Hidalgo se vuelca a dicho proyecto, pero que la siguiente generación, la de los románticos, descarta el proyecto de independencia literaria de la misma manera en que los modernistas lo harán después con los románticos. Por lo mismo, "la generación se renueva en el descontento y la promesa" (1928: 243); descontento de su presente, promesa que cada generación hace al futuro. Ante el problema de tener una lengua en común con España, el escritor americano tiene que buscar el "acento inconfundible" (ibídem: 251) con el ansia de perfección como norma (ibídem). Henríquez Ureña insiste en la importancia de hacer historia literaria, una síntesis que ponga en circulación "tablas de valores: nombres centrales y libros de lectura indispensables" (ibídem: 255). La Colección sigue esta lógica.

Uno de los temas importantes en la obra de Henríquez Ureña es la posición de América como centro. Esta centralidad se observa, por ejemplo, en "Barroco en América" (1940), cuando dice: "América creó en el siglo XVII su gran estilo barroco de construcción y ornamentación, que a veces refluyó sobre España, dueña de otro bien distinto, y aun atravesó los Pirineos, si no me engaña la capilla de la Virgen en la catedral de Perpiñán" (1940: 81). La tradición americana que plantea Henríquez Ureña surge de una relectura general del barroco; encuentra el barroco en la arquitectura y nombra a la par a Sor Juana. Lo que podemos observar en los trabajos de Henríquez Ureña y en su correspondencia con Cosío Villegas es la americanización del barroco, que permite una mirada al pasado en busca de la construcción de una tradición literaria que integre y tenga como elemento constitutivo el pasado virreinal. Al retomarlo, la tradición que había relegado a Góngora durante todo el siglo XVIII, se reconstituye e integra en sus formas a la estética barroca, ya no como un elemento discordante que pone en entredicho la autonomía del campo cultural latinoamericano, sino como la forma que es a la vez el origen y la pervivencia de su literatura.

Irlemar Chiampi propone que la reapropiación del barroco como herramienta de legitimidad histórica se afianza por su americanización y por la propuesta de Lezama Lima del barroco como el paradigma que moldea el hecho americano (2000: 21-24). Los escritores van en busca de referentes que ayuden a afincar su voluntad latinoamericanista. En esta búsqueda, encuentran que Sor Juana es un ícono propio para la revaloración histórica. Por ejemplo, Mariano Picón Salas, al distinguir entre el barroco como un período histórico y como muestra de un barroco literario de Indias, comenta que, en el caso de Sor Juana, su obra es paradigmática del barroco americano, pues "todos los valores y los enigmas del Siglo Barroco" se encuentran en ella, que escribe "en medio de la degeneración estética" (1969: 143). Para él, Sor Juana representa "el drama de la artificialidad y represión de nuestro barroco americano" (ibídem: 146) y, aun así, la considera americana (ibídem: 122). Por su parte, Lezama Lima escribe que, con la obra sorjuanina, el barroco "alcanza su plenitud y la plenitud del idioma poético en sus días" (2001: 106); con "Primero sueño", "el sueño y la muerte, alzándose por ese conocimiento poético la misma vivencia del conocimiento mágico" (ibídem: 109), como no sucederá sino hasta "Muerte sin fin" de José Gorostiza, al ser, ambos, "microcosmos poéticos" (ibídem: 110). Así, Lezama Lima, además de encontrar legitimidad en Sor Juana como insignia del barroco, encuentra en su poesía la plenitud de la poética del continente, la misma que traza Gorostiza hasta el Contemporáneo. 
De una manera similar a Lezama Lima, pero con una postura distinta en cuanto al significado del barroco, Carpentier lo concibe como universal y atemporal; lo postula, al igual que Eugenio D'Ors, como "una constante humana" (2002: 336) presente en América, aun antes de la Conquista, que se verifica y se renueva. El lenguaje capaz de expresar la constante histórica, la pulsión que, según él, emana del sincretismo americano, es lo real maravilloso. La americanización del barroco por parte de los escritores mencionados desemboca en una nueva interpretación: el neobarroco. De esta manera lo presenta Severo Sarduy, quien busca crear una síntesis entre el barroco literario (tomado del pasado) y su reapropiación en el siglo XX. Sarduy adjudica un valor revolucionario al neobarroco, una manera de ser en su presente a partir de la reinterpretación del pasado (2000: 184). En estas interpretaciones del barroco americano y del neobarroco, la monja tiene un lugar central, es el referente y el ejemplo que adapta al presente.

Al fin, después de estar sugiriéndolo desde 1914, Pedro Henríquez Ureña puede integrar las Obras completas de sor Juana como referente fundamental de la tradición americana. Sor Juana deja de ser novohispana, de la manera en que había sido leída en el siglo XIX, para convertirse en referente de la construcción de una tradición propiamente americana. La herencia del dominicano es reconocida por Méndez Plancarte en su edición sorjuanina. Además de seguir tangencialmente la delimitación de Henríquez Ureña en cuanto a la separación de los volúmenes, explícitamente reconoce la deuda intelectual con el dominicano: "Desde Pedro Henríquez Ureña, en 1914 - y luego de un vasto clamor de muchos-, se ha insistido en la urgencia de una cabal y digna reedición de las Obras de nuestra Musa, y aun llegaron a darse algunos pasos preliminares, aunque siempre hasta ahora fallidos" (1976: xlii).

Finalmente, los deseos de Henríquez Ureña se materializan. Se da un cambio en la recepción sorjuanina, como bien explica Lezama Lima: "Cuando era un divertimento, en el siglo XIX, más que la negación, el desconocimiento del barroco, su campo de visión era un extremo limitado, aludiéndose casi siempre con ese término a un estilo excesivo, rizado, formalista, carente de esencias verdaderas y profundas, y de riego fertilizante" (2001: 89). En el cambio a la valoración favorable, es crucial el papel que desempeñó Henríquez Ureña. En la integración de Sor Juana como agente fundamental del barroco americano se observa una apropiación que, como explica Perelmuter, muestra "esa tendencia a quererla asimilar a la época del lector, o a sus zonas de convergencia (estética, religiosa, nacional, sexual) expresan, me parece, el asombro compartido por sus lectores al enfrentarse a una escritora de la altura de Sor Juana" (2004: 123) con lo que se crea una "figuración imaginaria de Sor Juana, fácilmente plegable o moldeable de acuerdo a las necesidades o la óptica de su lector" (Ibídem). En la figuración de mediados del siglo XX, el barroco, en general, y Sor Juana, en particular, dan cuenta de una relectura del pasado y su incorporación como parte de una configuración americana. La importancia de las Obras completas como parte de una voluntad unificadora en la Colección Biblioteca Americana consiste en situarla en un contexto de enunciación en el que se pretende, por un lado, configurar una tradición y, por otro, dar a conocer y hacer accesibles los textos que la conforman. 


\section{Q Bibliografía}

»AA. VV. (1874). Composiciones leídas en la velada literaria que consagró el Liceo Hidalgo a la memoria de Sor Juana Inés de la Cruz la noche del 12 de noviembre de 1874, aniversario del natalicio de la ilustre poetisa. México: Imprenta del Porvenir.

» Abreu Gómez, E. (1934). Sor Juana Inés de la Cruz: bibliografía y biblioteca. México: La Voz Nueva.

»Abreu Gómez, E. (1938). Semblanza de Sor Juana. México: Ediciones Letras de México.

"Alatorre, A. (2007a). Las redondillas de Sor Juana contra los „hombres necios“: un siglo de fama (1818-1910). En Lara, L. F.; Yunen Ortega, R. y Tenorio, M. L. (eds.). De amicitia et doctrina: Homenaje a Martha Elena Venier, pp. 44-75. México: El Colegio de México.

"Alatorre, A. (2007b). Sor Juana a través de los siglos (1668-1910). Tomo II. México: El Colegio de México.

»Carpentier, A. (2002). Lo barroco y lo real maravilloso. En Ensayo cubano del siglo XX: antología, pp. 333-356. Hernández, R. y Rafael Rojas, R. (selec., pról. y notas). México: Fondo de Cultura Económica.

»Chiampi, I. (2000). Barroco y modernidad. México: Fondo de Cultura Económica.

»Clark de Lara, B. (2008). Hacia una historia del Liceo Hidalgo y la construcción de la literatura mexicana. En Curiel Defossé, G. y Clark de Lara, B. (coords.). Aproximaciones a una historia intelectual. Revistas y asociaciones literarias mexicanas del siglo XIX, pp. 87-104. México: Universidad Nacional Autónoma de México.

"Cosío Villegas, D. (s.f.). Correspondencia con Pedro Henríquez Ureña. Legajo 155 conservado en el Archivo Histórico del Fondo de Cultura Económica de México.

» Fumagalli, C. A. (2018). Sor Juana Inés de la Cruz: articulaciones entre obra y archivo en los preliminares de sus ediciones originales. Anclajes, vol. XXII, $n^{\circ}{ }^{\circ}$ : 37-53.

» González-Stephan, B. (2002). Fundaciones: canon, historia y cultura nacional. La historiografía literaria del liberalismo hispanoamericano del siglo XIX. Madrid/ Frankfurt: Iberoamericana/Vervuert.

» Henríquez Ureña, P. (1928). Seis ensayos en busca de nuestra expresión. Buenos Aires: Babel.

» Henríquez Ureña, P. (2004a). Barroco en América En Martínez, J. L. (ed.). Estudios Mexicanos. México: Fondo de Cultura Económica.

» Henríquez Ureña, P. (2004b). Sor Juana Inés de la Cruz. En Martínez, J. L. (ed.). Estudios mexicanos, pp. 59-80. México: Fondo de Cultura Económica.

» Henríquez Ureña, P. (2011). En pro de una edición definitiva de Sor Juana. En Prolija memoria. Primera época, vol. 5, no 1-2: 231-242.

"Herrera Zapién, T. (2005). De Abreu Gómez a Méndez Plancarte: entre fantasmas barrocos y ausencias latinas. En Lorenzano, S. (ed.). Aproximaciones a Sor Juana, pp. 151-158. México: Universidad del Claustro de Sor Juana/Fondo de Cultura Económica. 
» Jiménez del Campo, P. (2005). Sor Juana: modelo de apropiación crítica. En América: Cahiers du CRICCAL, vol. 1, no 33: 213-219. Disponible en: https://www. persee.fr/doc/ameri_0982-9237_2005_num_33_1_1725

» Juana Inés de la Cruz, sor (1951-1957). Obras Completas. 4 tomos. Alfonso Méndez Plancarte (ed.) I-III y Alberto Salceda (ed.) IV. México: Fondo de Cultura Económica.

»Lezama Lima, J. (2001). La expresión americana. México: Fondo de Cultura Económica.

"Lezama Lima, J. (1976). Introducción. En Sor Juana Inés de la Cruz, Obras completas. Tomo I. Lírica personal, pp. vii-Ixviii. México: Fondo de Cultura Económica.

» Méndez Plancarte, A. (1982). Crítica de críticas sorjuaninas. México: Ediciones Las Hojas de Mate.

"Perelmuter, R. (2004). De la excepcionalidad a la impostura: Sor Juana Inés de la Cruz ante la crítica (1700-1950). En Los Límites de la femineidad en Sor Juana Inés de la Cruz. Madrid/Frankfurt: Iberoamericana/Vervuert.

"Pérez González, A. M. (2018). Censura, crítica y legitimación en los paratextos de la literatura novohispana (siglos XVI-XVIII). Tesis doctoral. México: El Colegio de México.

"Picón Salas, M. (1969). De la conquista a la independencia. Tres siglos de historia hispanoamericana. México: Fondo de Cultura Económica.

»Quijano, M. (2005). José María Vigil y la recuperación del pasado colonial en la primera historia de la literatura mexicana. En Literatura Mexicana, vol. XXVI, no 1: 65-82.

»Sánchez Prado, I. (2010). Canon “interruptus": la Antología del Centenario en la encrucijada de 1910. En Revista de Crítica Literaria Latinoamericana, año 36, no 71: 55-74.

"Sarduy, S. (2000). El barroco y el neobarroco. En César Fernández Moreno, C. (coord.), América Latina en su literatura, pp. 167-184. México: Siglo XXI/UNESCO.

"Sheridan, G. (1985). Los Contemporáneos ayer, 2ª reimpresión. México: Fondo de Cultura Económica.

»Stanton, A. (1998). Sor Juana entre los Contemporáneos. En Inventores de tradición: ensayos sobre poesía mexicana moderna, pp. 63-89. México: El Colegio de México.

"Tello Solís, E. J. . (2008). El personaje Abreu Gómez. En Revista de la Universidad Autónoma de Yucatán, vol. 22, nº 243-244: 11- 23.

» Tenorio, M. L. (2008). A propósito de Sor Juana a través de los siglos. En Nueva Revista De Filología Hispánica, vol. 56, ํㅡ 2: 505- 522.

"Tenorio, M. L. (2018).Prólogo. Para leer a Sor Juana. En Ecos de mi pluma: Antología en prosa y verso, pp. 2-36. México: Penguin Random House.

" Urbina, L. G. (1910). Estudio preliminar. En Urbina, L. G.; Henríquez Ureña, P. y Range, N. (eds.), Antología del Centenario. Estudio documentado de la literatura mexicana durante el primer siglo de Independencia, pp. I-CCXLV. LI. Primera Parte (1800-1821). Vol. Primero. México: Imp. de Miguel León Sánchez.

»Weinberg, L. (2014). Biblioteca Americana. Una poética de la cultura y una política de la lectura. México: Fondo de Cultura Económica. 
